\title{
Social Marketing: Planning Before Conceiving Preconception Care
}

\author{
Christine E. Prue • Katherine Lyon Daniel
}

Published online: 6 June 2006

(C) Springer Science+Business Media, Inc. 2006

\begin{abstract}
Social marketing approaches can help to shape the formation of and to create demand for preconception care services. This article describes four components of social marketing, often referred to as the 4 P's, that should be carefully researched and set in place before a national effort to launch and sustain preconception care services is pursued. First, the product or package of services must be defined and adapted using the latest in scientific and health care standards and must be based on consumer needs and desires. Second, the pricing of the services in financial or opportunity costs must be acceptable to the consumer, insurers, and health care service providers. Third, the promotion of benefits must be carefully crafted to reach and appeal to both consumers and providers. Fourth, the placement and availability of services in the marketplace must be researched and planned. With the application of market research practices that incorporate health behavior theories in their exploration of each component, consumer demand for preconception care can be generated, and providers can take preconception care to the market with confidence.
\end{abstract}

Keywords Social marketing · Health communication · Preconception care · Preconception health · Behavior theories

\section{Introduction}

Preconception care (PCC) is a critical component of maternal and child health that does not currently have a strong foothold in our health care delivery system

C. E. Prue $(\bowtie) \cdot$ K. L. Daniel

Centers for Disease Control and Prevention, National Center on Birth Defects and Developmental Disabilities, 1600 Clifton Rd. NE, MS E86, Atlanta, GA 30333, USA e-mail: cprue@cdc.gov
[1-3]. A more detailed discussion of how preconception care supports preconception health ( $\mathrm{PCH}$ ) and ultimately healthy pregnancies and babies is found in the introduction of this volume. In order to market a health product or service, it is important to understand what people want or need before it is developed, and then to provide them with the opportunity to meet those needs in a way that is compelling to them and also improves a mutually beneficial outcome for patients and their providers: a healthy baby. Of course, unlike commercial products, the outcome of preconception care services (a healthy pregnancy and a healthy baby), cannot be guaranteed; there are many factors that influence pregnancy and birth outcomes that are outside a mother or healthcare provider's realm of control. Despite the risk of adverse outcomes, there is much a woman, her partner, and her health care provider can do together preconceptionally to optimize pregnancy and birth outcomes. Social marketing is defined as "the application of commercial marketing technologies to the analysis, planning, execution, and evaluation of programs designed to influence voluntary behavior of target audiences in order to improve their personal welfare and that of society" (4). The social marketing process involves identifying an effective "marketing mix" of product, price, promotion, and place with the goal of offering an exchange that has clear and compelling benefits, minimal barriers, and an advantage over the competition. In plain language, that means setting up a situation so that future parents, health care professionals, and health insurers can all benefit and support a common goal of healthy women, healthy pregnancies, and healthy babies. To accomplish this, resources first need to be dedicated to conducting audience and market research using a systematic approach at all levels. Often, health behavior theories can be used to shape the development of new products or services as well as to evaluate their effectiveness in achieving intended outcomes. Table 1 lists some of the theories and frameworks 
Table 1 Theories and frameworks applicable to guiding research on the 4 P's of social marketing preconception care services

\begin{tabular}{|c|c|c|c|}
\hline Marketing component & Theory or framework & Focus of the theory or framework & Relevant constructs or concepts \\
\hline \multirow[t]{2}{*}{ Product } & Social marketing & $\begin{array}{l}\text { The application of marketing techniques to } \\
\text { the design, implementation, and evaluation } \\
\text { of programs designed to facilitate voluntary } \\
\text { exchanges of mutual benefit and improved } \\
\text { personal well-being and societal welfare }\end{array}$ & $\begin{array}{l}\text { Formative research; Market } \\
\text { segmentation; Competitive analysis }\end{array}$ \\
\hline & Diffusion of Innovation & $\begin{array}{l}\text { The spread of new ideas, products, or } \\
\text { services within a society or from one } \\
\text { society to another; focus on innovation }\end{array}$ & $\begin{array}{l}\text { Relative advantage; Compatibility; } \\
\text { Complexity; Trialability; } \\
\text { Observability }\end{array}$ \\
\hline \multirow[t]{2}{*}{ Price } & Social cognitive theory & $\begin{array}{l}\text { The interaction between personal factors, } \\
\text { environmental factors, and human behavior }\end{array}$ & $\begin{array}{l}\text { Reciprocal determinism; Behavioral } \\
\text { capability; Expectations; } \\
\text { Self-efficacy; Observational } \\
\text { learning; Reinforcements }\end{array}$ \\
\hline & Health belief model & $\begin{array}{l}\text { The perceptions of threat posed by a health } \\
\text { problem, the benefits of avoiding the threat, } \\
\text { and factors influencing the decision to act }\end{array}$ & $\begin{array}{l}\text { Perceived benefits; Perceived } \\
\text { barriers; Cues to action; } \\
\text { Self-efficacy }\end{array}$ \\
\hline \multirow[t]{2}{*}{ Promotion } & Diffusion of innovation & $\begin{array}{l}\text { The spread of new ideas, products, or } \\
\text { services within a society or from one } \\
\text { society to another; focus on diffusion }\end{array}$ & $\begin{array}{l}\text { Communication channels; Social } \\
\text { systems/networks }\end{array}$ \\
\hline & $\begin{array}{l}\text { Precaution adoption process } \\
\text { model }\end{array}$ & $\begin{array}{l}\text { The journey from lack of awareness to action } \\
\text { and maintenance in dealing with hazards; } \\
\text { acknowledge inherent risk }\end{array}$ & $\begin{array}{l}\text { Unawareness; Unengaged; } \\
\text { Decision-making; Acting }\end{array}$ \\
\hline Place & Communication theory & $\begin{array}{l}\text { The different types of communication that } \\
\text { affect health behavior }\end{array}$ & $\begin{array}{l}\text { Media Exposure; Media effects; } \\
\text { Agenda setting; Framing }\end{array}$ \\
\hline
\end{tabular}

Note. For easy-to-understand information about the theories, frameworks, constructs, and concepts listed in this table, go to http://www.nci.nih.gov/theory/pdf for a downloadable copy of NCI's "Theory at a Glance—A guide for health promotion practice"

that can be applied to addressing the 4 P's of preconception care services (5).

Viewing health care services as a business, and using language such as "marketing" and "sales," may be uncomfortable to some who prefer to view the process of having a baby as a natural, emotional and deeply personal part of the human experience. However, the notion of providing preconception care as a service could very well benefit from a well-conceived and constructed social marketing research plan and execution that acknowledges and embraces the emotions of the patient and her partner. Thus, thinking about developing a social marketing plan to support preconceptional health care could help to ensure that babies are born with the best start in life.

One example of how the business market has taken advantage of this type of opportunity is the development of a bank that preserves umbilical cord blood (UCB). The original idea in 1988 was a not-for-profit resource bank of donated cord blood for those who might need it for transplantation purposes (6). However, since that time, enterprising companies have created a market and generated the "need" for cord blood storage for a couple's own child-even though the chances they will personally need it are roughly 1 in 10,000 . Companies who forecast a profit in this service use direct marketing strategies to expectant couples through diaper companies and magazine subscriptions. Attempts to patent the cryopreservation processes and limit competition have raised legal, ethical and clinical questions - but the market to sell the idea of cord blood collection and preservation is lucrative and the demand is increasing (7). Advocates of preconception care can learn important lessons from the UBC preservation business marketing executives who market, sell and provide services to a similar audience.

\section{Product}

Preconception care (PCC) is the product or concept we are trying to "sell" as a precursor for assuring PCH: The need for PCC is well-supported by research in the health field $(1,8,9)$. The product has been described in a number of publications as including a "bundle" of services most often including screening of the following elements: reproductive history; medications and potential teratogens; environmental exposures; age, family medical and genetic history; infections and immunizations; social habits and risk behaviors; diet and exercise; and any chronic medical conditions $(10,11)$. Preconception care is supported by a number of practitioner specialties $(1,12,13)$ and was related to a Healthy People 2000 goal (14). Whereas some aspects of PCC have more evidence linking them to improved outcomes (e.g., folic acid for NTDs and glycemic control for diabetes) and others have 
less evidence (e.g., genetic counseling and smoking cessation), the need for a more integrated approach to health prior to conception enjoys a broad range of support (15-18). Nevertheless, there has been little support of PCC in a systematic manner in the US or other countries as a standard of care (2, 19-21). A social marketing approach can provide an important support for that uptake by beginning with a critical first step-defining the attributes of the "product" we are selling from a potential consumer's point of view-which involves formative research with consumers. Key questions for the research may include: what do women and their partners want, when are PCC services optimally delivered, and what needs would have to be met in order for women or couples to value PCC services? This approach dictates that it is important to understand the perspective of the patient (and her partner) as more than just as consumers of health care services, but also by understanding their other perceived needs and desires in order to provide a satisfactory exchange. Couples may not view the decision to start a family as a medical decision, so this may be one reason the health care delivery system is more likely to be engaged some time after conception. In fact, couples may assess their financial readiness to start a family before their physical, emotional, or relationship readiness for this life-altering decision. The research that is an integral part of the social marketing process can help us to understand the decision-making dynamic (or lack thereof) that couples may engage in prior to conception. While only $50 \%$ of pregnancies are planned in the U.S., understanding how couples think about pregnancy may be a good place to start. Frishman suggests other "windows of opportunity" that could be explored among women including when women inquire about birth control, obtain negative pregnancy tests, or have recently delivered a baby (22). Wallerstedt et al. suggest that preconceptional health promotion and interconceptional counseling may be even more beneficial for parents who have had previous perinatal or infant loss (23). Social marketing research can help provide an understanding of the motivations and barriers for and against preconception care. A social ecological perspective (24) encourages program planners to look at multiple levels of influence: 1) intrapersonal or individual level; 2) interpersonal or social level; 2) institutional or organizational level; 4) community level; 5) and public policy or societal level. A major corporation preparing to launch a new product for women who might become pregnant (e.g., a new home pregnancy test) would never begin without spending substantial time and resources on understanding the target market and identifying the product attributes that will appeal to that market, while also knowing what the competitive environment is before they make investments in product development that might not have a profitable return. Product attributes can have a major impact on both the speed and extent of a product's uptake by a target population. Rogers' diffusion of innovation theory (25) identified a number of product attributes including relative advantage (is the product better than what it will replace?), compatibility (does the product fit with the intended audience?), complexity (is the product easy to use?), trialability (can the product be "tried out" before making a decision to purchase it?), and observability (are the results of the product visible and measurable?). Program planners can position their products effectively in the marketplace if they maximize their product's appeal by addressing these important product attributes.

\section{Price}

The next aspect of social marketing research to increase the supply of and demand for preconception care is pricedefining the costs to patients, providers and insurers, measured in time and/or money, in order to have quality and timely preconception care. Once the product attributes have been defined and developed to address PCC services in a mutually satisfactory way for women, health care professionals and insurers, then appropriate pricing is vital to allow for uptake. Lowering the intangible (nonfinancial) costs to patients can be facilitated by using some common standards of social marketing: the most effective health messages often incorporate emotional connections and values to make behavior change more appealing. Also, the best social marketing approaches make it easy for people to make changes that the service providers want them to-in this case in order to be healthy, and have a healthy pregnancy and baby. In addition to appeal and ease, some marketers would say that a new product would have to have relative advantage over products currently in the marketplace. "New and improved" labeling does matter when a product is introduced. A product's relative advantage can often be framed as more appealing and/or easier, but at its core it must meet a customer need or desire. Appealing and easy actions to improve health are perceived as less costly by the patient or customer. Social cognitive theory (26) which addresses the interaction between personal, environmental, and behavioral factors is commonly used to understand many facets of a person's expectations of outcomes from performing a behavior, environmental contexts (helps and hindrances) related to the behavior, experiences in performing the behavior (positive or negative), and efficacy (ability/confidence) in performing the behavior. These are just a few of the ways in which the pricing can build on the positive product attributes developed in the first step. It also helps that the outcome-a healthy pregnancy and baby-is a highly valued and very tangible benefit for those who want it.

The pricing for a health care organization is more complicated. Cost-effectiveness studies and business case studies 
need to document how the organization's PCC service costs compare with treatment of preventable health conditions. Balancing financial overhead and time pressures in these times of managed care may be a real challenge-and particularly so for reaching women who may have unplanned pregnancies. The greatest challenge may be weighing the intangible costs and benefits against the financial costs: How much preconceptional folic acid counseling is worth a child being born without a lifelong disability like spina bifida? How many smoking cessation sessions balance out the costs of a premature/low birth weight baby who might spend his first months of life in the NICU? How many fewer patients might a health care professional have time to see and bill for when pregnancy counseling they do for people with genetic conditions takes up more time? And what additional patient education messages, addressing chronic or acute health issues, are not being delivered during a regular well visit because the health care professional's time is being used discussing preconception health issues? The health care provider medical office may well not be the best and/or most efficient way to market preconception care services to consumers in many cases. The practicing physician may also not be the first or best person to deliver the preconception care message. The goal of a good pricing strategy is to find an effective and innovative way to reach the target market while reducing the costs to both the health care delivery system and the consumer.

\section{Promotion}

After the product has been defined as a generally acceptable package of PCC services, and the price to individual and organization is determined to be mutually beneficial, how can a social marketing approach diffuse it into common practice and social norms? This is where the promotion comes into play among two key audiences: 1) people who would like to be providers (or sellers) of the product and 2) people who would be consumers (or buyers) of the product. Often, promotion is thought to focus solely on creating demand among consumers for a particular product, and the promotion process is what most people typically think of as marketing or advertising. However, whereas most businesses prefer to have products "on the shelf" to meet the needs of consumers proactively, consumers are more influential than ever before in demanding that a product appears on their vendor's shelves. PCC could very well become a product that consumers themselves create demand for-especially since the health care industry already sees the value of preconception care services but has not built a product offering that delivers what they believe to be important. Once the product and pricing attributes are developed, then promoting the product among potential buyers and sellers could be done using a number of communication theories that provide guidance on what types of communication messages and media vehicles (e.g. communication channels) can achieve in terms of exposure and effects. In fact, trade shows and product expositions are a major venue for new products to be introduced to businesses who sell products. Health care provider/insurer conferences, continuing medical education efforts, and medical school training could be venues for promoting PCC services among potential providers (27). Because the product attributes have already been defined as a benefit, and pricing has been addressed in the previous step, promotion should be a matter of convincing both buyers and sellers that they are acting in their own best interests. After promotion has helped to generate consumer demand for the product, PCC is an opportunity for current health care professionals, insurers and those in the business of health to expand their services-as in a classic new product offering. An important way for organizations to justify offering these services is to demonstrate an immediate benefit (perhaps in sales of other products and services) in addition to longer term benefits (perhaps fewer complicated pregnancies, lower malpractice premiums, fewer patients who need life-long care). And of course, the actual benefits would be determined through a process of market research with stakeholders-such as patients, health professionals and insurers (Table 2). Addressing current barriers and how to overcome them is a major contribution of the promotion activities. Using innovative ways to promote preconception care services not only can be modified from general market promotions but also by taking advantage of existing opportunities to deliver tailored "gateways/pathways" to PCC services. These could vary from fertility treatment centers to other family planning arenas. Whether a woman is seeking to become pregnant or trying to avoid becoming pregnant (but preserving her options for the future), she is a consumer who may be fertile ground, so to speak, for preconception care services. A challenging part of promoting PCC services will be figuring out how to move the thinking of a "now-oriented" consumer towards more "future-oriented" events; especially because future outcomes could happen earlier than planned/anticipated. This promotion could take advantage of additional opportunities such as involving male partners and other influential people in women's lives-and also taking a lifelong approach to health $(13,28)$. Another challenge to promoting PCC services will be addressing the ethical aspects of promoting a product that cannot guarantee outcomes: Not every woman who chooses and uses preconception care services will be able to have a healthy pregnancy or a healthy baby. In fact, it might even be the case that unhealthy women (e.g. those with chronic diseases or other medical conditions) are the first to want and use preconception care services because they know that their poor health status makes pregnancy a hazardous situation for themselves and their baby. The importance of 
Table 2 Sample social marketing questions for selected stakeholders of preconceptional care services

\begin{tabular}{|c|c|c|c|}
\hline & Consumers & Health care providers & Insurers \\
\hline $\begin{array}{l}\text { Product - What action must be } \\
\text { taken by each audience (e.g., } \\
\text { product, behavior, or policy) }\end{array}$ & $\begin{array}{l}\text { What does PCC services need to } \\
\text { look and feel like for consumers } \\
\text { to want/use/demand them? }\end{array}$ & $\begin{array}{l}\text { What does PCC services need to } \\
\text { look and feel like for busy health } \\
\text { care providers to want to offer } \\
\text { them? }\end{array}$ & $\begin{array}{l}\text { What does PCC services need to } \\
\text { look and feel like for health } \\
\text { insurers to want to cover this } \\
\text { service? }\end{array}$ \\
\hline $\begin{array}{l}\text { Pricing - Why would they want to } \\
\text { do it? }\end{array}$ & $\begin{array}{l}\text { What is the value of PCC services } \\
\text { and what would they be willing } \\
\text { to pay for them? }\end{array}$ & $\begin{array}{l}\text { What is the value for offering } \\
\text { PCC services to patients and } \\
\text { what would it cost to offer them? }\end{array}$ & $\begin{array}{l}\text { What is the return on investment } \\
\text { for including PCC services as a } \\
\text { covered service? }\end{array}$ \\
\hline $\begin{array}{l}\text { Promotion - How will each } \\
\text { audience be told about the what, } \\
\text { why, where, and how? }\end{array}$ & $\begin{array}{l}\text { How will PCC services be } \\
\text { publicized and made available to } \\
\text { consumers in a way that they are } \\
\text { attractive, affordable, and } \\
\text { accessible? }\end{array}$ & $\begin{array}{l}\text { How will PCC services be } \\
\text { presented to health care } \\
\text { providers so that they are willing } \\
\text { and able to offer them? }\end{array}$ & $\begin{array}{l}\text { How will PCC services be } \\
\text { presented to insurers so that they } \\
\text { are willing and able to reimburse } \\
\text { for them? }\end{array}$ \\
\hline $\begin{array}{l}\text { Place - Where can they do the } \\
\text { action needed? }\end{array}$ & $\begin{array}{l}\text { What settings/locations are most } \\
\text { acceptable, appropriate, and } \\
\text { accessible for providing PCC } \\
\text { services? }\end{array}$ & $\begin{array}{l}\text { What settings/locations are most } \\
\text { acceptable, appropriate, and } \\
\text { accessible for offering PCC } \\
\text { services? }\end{array}$ & $\begin{array}{l}\text { What forums or conferences can } \\
\text { instigate productive discussions } \\
\text { about including PCC services as } \\
\text { a covered expense? }\end{array}$ \\
\hline
\end{tabular}

recognizing hazards and taking precautionary actions to protect health, which are addressed in the precaution adoption process model (29), may be relevant in promoting PCC services in a manner that acknowledges pregnancy as having inherent risk for both the mother and the unborn baby.

\section{Place}

It is useful to ask how PCC services could be placed, or distributed, to women across their reproductive lifespan in a manner that addresses social marketing's call toward mutually satisfactory exchanges, and how the placement of PCC services could affect their delivery. What components of PCC might change across the life span (e.g. early health promotion/contraception/STD infection/vaccinations/others)? The high level of unintended pregnancies in the US-40-60\% for adults, $95 \%$ for teens (30)-is also a concern, because any approach that requires a self-selection into the audience will miss about half of the pregnancies. Some authorities have suggested a lifelong approach to preconceptional health - throughout the lifespan of a women's potential fertility (say, 10-50 years of age) and an approach that may move women from one set of services and questions into another $(2,31)$. Social marketing can help by determining in the early phases what women and health care professionals want, and thus ensuring that supply can be ready when the demand is articulated. Health care professionals need to be involved in the design of those PCC services that they would deliver, and must do so in the context of what they would want to deliver - and those they would benefit from. Women report that one of their most influential sources of health information is their own health care professional, who knows them, their medical history and their concerns (32). Health care professionals and their medical staff may be the front line "sales people" for preconceptional care; if doctors never offer their patients the opportunity to "buy" this product, it will go nowhere. Medical professionals who are trained on the benefits of the product (e.g., by inclusion in medical school training and on medical board exams) and rewarded for using it (by reducing malpractice premiums for example) will find it more acceptable and worthwhile to integrate the practice into the time pressures of the busy medical office. Once a physician selection is made, patients visit for an acute problem, management of a chronic condition, and for routine checkups. Placement market research will help to define how PCC services may fit into each of these areas. This integrated vision of PCC could become part of the core training curricula for various medical professionals-more than an option during continuing education. This strategic preparation for placement also ensures that when the increased demand from the consumer begins to be evident at the health care provider office, the medical professionals in that office will know how to respond to that demand, and have the knowledge and systems in place to do so. Existing "bundles" of services that can be prepackaged to respond to this demand have in some cases been developed $(33,34)$. If the research in the first phase shows that the busy medical office is not the best location for providing PCC services, then alternate placement sites must be identified.

\section{Conclusion}

The best marketing and sales happen when the product has the qualities that a consumer wants and that a seller wants to provide. PCC must meet the needs and desires of patients, health professionals and insurers in order to be successfully 
adopted in the United States. For women and their families, that may mean believing that a healthy, wanted baby is in their future. For doctors, that may mean finding a way to give healthy women the preventive services they want and need while still dealing with the urgent care of their sick patients. For insurers it may mean a balance in service provision to meet both short and long term financial goals. But market research is needed to actually define exactly what the benefits are to each of those groups. And it is likely to be that the satisfactory exchange is more than just a purely medical application of clinical services. Consumers across the US are willing to spend $\$ 3.00$ to drink what is essentially a 50 cent cup of coffee, but they are experiencing something more than the product's primary attributes (e.g., flavor, caffeine) but also the positive associations with the product (e.g., funky, cool). In the same way, consumers can tell us how they would like to experience preconception health care services (35). All of us need to understand that if we market and sell it as the best experience possible, PCC could contribute to healthier babies, fewer medical treatment costs, and a healthy next generation that thinks about pregnancy in a whole different way.

\section{References}

1. Hobbins D. Full circle: The evolution of preconception health promotion in America. JOGNN 2003;32(4):516-22.

2. Moos MK. Preconceptional health promotion: Progress in changing a prevention paradigm. J Perinat Neonat Nurs 2004;18(1):213 .

3. Chazotte C, Freda MC. Collaboration among four medicine specialties to develop a curriculum on preconception health. Acad Med 2001;76(5):522-23.

4. Andresasen AR. Marketing social change: Changing behavior to promote health, social development, and the environment. JosseyBass; 1995.

5. U.S. Department of Health and Human Services. Theory at a Glance-A guide for health promotion practice. 2nd ed. NIH Publication No. 05-3896, September 2005.

6. Nelkin D, Andrews L. Homo economicus: Commercialization of body tissue in the age of biotechnology. Hastings Center Report 28, No. 5 (1998): 30-9.

7. Sugarman J, Kaalund V, Kodish E, Marshall MF, Reisner EG; Wilfond BS, Wolpe PR. Ethical issues in umbilical cord banking. JAMA 1997;278:938-43.

8. De Weerd S, van der Bij AK, Cikot RJLM, Braspenning JCC, Braat DDM, Steegers EAP. Preconception care: A screening tool for health assessment and risk detection. Prev Med 2002;34:50511 .

9. ACOG technical bulletin No. 2005. Preconceptional care. Int J Gynaecol Obstet 1995;50:201-7.

10. Frey K. Preconception care by the nonobstetrical provider. Mayo Clin Proc 2002;77(5):469-73.
11. Korenbrot C, Steinberg A, Bender C, Newberry S. Preconception care: A systematic review. Matern Child Health J 2002;6(2):7588 .

12. Wille MC, Weitz B, Kerper P, Frazier S. Advances in preconception genetic counseling. J Perinat Neonat Nurs 2003;18(1):28-40.

13. Brundage SC. Preconception health care. Am Fam Physician 2002;65(12):2507-14.

14. U.S. Dept. of Health and Human Services, Public Health Service. Healthy People 2000: National Health Promotion and Disease Prevention Objectives (1990). DHHS Publication No. (PHS) 91-50212. Washington, DC: U.S. Government Printing Office.

15. Czeizel AE. Ten years of experience in periconceptional care. Eur J Obstet Gynecol Reprod Biol 1999;84:43-9.

16. Kendrick JM. Preconception care of women with diabetes. J Perinat Neonat Nurs 2004;18(1):14-25.

17. Moos MK. Preconceptional wellness as a routine objective for women's health care: An integrative strategy. JOGNN 2003;32(4):550-6.

18. Schrander-Stumpel C. Preconception care: Challenge of the new millennium? Am J Med Genet 1999;89:58-61.

19. Kim C, Ferrara A, McEwen LN, Marrero DG, Gerzoff RB, Herman WH, the TRIAD Study Group. Preconception care in managed care: The translating research into action for diabetes study. Am J Obstet Gynecol 2005;192:227-32.

20. Poppelaars FAM, Cronel MC, ten Kate LP. Current practice and future interest of GPs and prospective parents in pre-conception care in The Netherlands. Fam Pract 2004;21(3):307-9.

21. Heyes T, Long S, Mathers N. Preconception care. Fam Pract 2004;21(1):22-7.

22. Frishman G. Preconception counseling and care: A unique window of opportunity. Med Health R I 2003;86:16-8.

23. Wallerstedt C, Lilley M, Baldwin K. Interconceptional counseling after perinatal and infant loss. JOGNN 2003;32:533-42.

24. Quinn LA, Thompson SJ, Ott MK. Application of the social ecological model in folic acid public health initiatives. JOGNN 2005;34:672-81.

25. Rogers EM. Diffusion of innovations. 4th ed. New York, NY: Free Press; 1995.

26. Bandura A. Social foundations of thought and action: A social cognitive theory. Englewood Cliffs, NJ: Prentice-Hall; 1986.

27. Cullum AS. Changing provider practices to enhance preconceptional wellness. JOGNN 2003;32:543-9.

28. Yamey G. Sexual and reproductive health: what about boys and men? BMJ 1999;319(20):1315-6.

29. Weinstein ND. The precaution adoption process. Health Psychol 1988;7(4):355-86.

30. CDC. State-specific pregnancy and birth rates among teenagersUnited States, 1991-1992. MMWR 1995;44(37):677-84.

31. Misra DP, Bernard G, Allston A. Integrated perinatal health framework: A multiple determinants model with a life span approach. Am J Prev Med 2003;25(1):65-75.

32. Porter Novelli. ConsumerStyles 2005 survey. Unpublished raw data. Washington, DC: Deanne Weber; 2005.

33. Maier KM, Kirkham CM, Cheung EL, Grzybowski S. Pregnancy planning guide. Evidence-based information for prospective parents. Can Fam Physician 2002;48:1199-205.

34. Konchak PS. Preconception care: "VITAL MOM"-a guide for the primary care provider. JAOA 2001;101(2):S1-9.

35. Pine II BJ, Gilmore JH. The experience economy: work is theater $\&$ every business a stage: goods \& services are no longer enough. Harvard Business School Press; 1999. 